\title{
RESEARCH OF HYDROCARBON COMPOSITION AND PHYSICAL AND CHEMICAL PROPERTIES OF LIGHT DISTILLATE FRACTIONS OF CASPIAN OIL
}

\author{
E.K. Kaldykozov ${ }^{1}$, E. S. Tleubay ${ }^{1, *}$, G. E. Kaldygozova² \\ and B. A. Abdikerimov ${ }^{1}$ \\ ${ }^{1}$ M. Auezov South Kazakhstan University /Department of Oil Refining and petrochemistry, \\ Tauke Kahan av.5, 160001, Shymkent, Kazakhstan \\ ${ }^{2}$ Ahmed Yasavi International Kazakh-Turkish University/ Department of Traumatology- \\ Orthopedics and Oncology Turkestan, South Kazakhstan Region, B. Sattarkhanov Ave., 29 \\ *E-mail: yelzira.tleubayeva@bk.ru
}

\begin{abstract}
This article presents the results of a study of the physical and chemical properties and individual hydrocarbon composition of gasoline and kerosene-gas oil fractions of the Caspian field, Atyrau region. The detailed group hydrocarbon composition and commodity physical and chemical characteristics of gasoline, kerosene and diesel fractions are determined, as well as the influence of the parameters of the main technological factors - temperature, pressure and volume feed rate of raw materials on the output and quality of the target product. The optimal variant of its processing with the production of commodity oil products is proposed. It is shown that the Caspian oil field paraffin medium, mainly consists of light hydrocarbons with high yields of gasoline fractions (36,2\% wt.) and with a high content of hydrogen sulfide, sulfide and light mercaptan sulfur compounds, which require a special approach to their effective processing, and shows that in the process gidroliticheski processing of the received oil of the mixture oil of the Caspian Deposit significantly improves the physical and chemical properties: reduces sulfur, nitrogen and oxygen compounds. Light gasoline fraction (boiling point $62^{\circ} \mathrm{C}$ ) Caspian oil is effectively used as a valuable raw material for the process of catalytic cracking at existing refineries of the Republic of Kazakhstan as a raw material for the process of catalytic isomerization, and the resulting product-isomerize is used as a component of commercial high-octane environmentally friendly automobile gasoline and for the production of hydrocarbon solvents, kerosene and diesel fractions, and after their hydrocatalytic processing is used as a component for the production of jet and diesel fuel.
\end{abstract}

Keywords: Physical and Chemical Properties, Gasoline Fraction, Hydrogen Sulfide, Distillate Fraction, Chromatograph, Catalytic Isomerization, Hydrocarbon, Petroleum Product.

(C) RASĀYAN. All rights reserved

\section{INTRODUCTION}

The problem of studying the physical and chemical properties of oil from the promising Caspian field of the Republic of Kazakhstan is of great importance for finding the most rational ways to process them. The development of rational options for processing distillate fractions of Caspian oil allows us to effectively solve the problem of meeting the country's demand for high-quality motor and boiler fuels and raw materials for petrochemicals. There are no data in the scientific and technical literature describing the commodity and physical and chemical properties of light gasoline and medium distillate fractions of oil from the Caspian field. Therefore, the choice of optimal technological processes for the development of rational options for processing light distillate fractions of Caspian oil allows us to effectively solve the problem of meeting the country's needs for high-quality automobile, jet, diesel boiler fuels and oil and lubricants, as well as raw materials for petrochemicals. It should be noted that the potential reserve of the studied oil is very large, so specific and targeted special research is important and relevant. 
RASĀYAN J. Chem.

Vol. 13 | No. 4 |2639-2645| October - December | 2020

\section{EXPERIMENTAL}

The object of this research is to select and develop the optimal technology for processing crude oil, a mixture of oil from the Caspian field. When studying the object, various standard methods of analysis for petroleum products were used following the relevant GOST-s. ${ }^{1,4}$

Identification of potential content physical and chemical properties and commodity characteristics of individual distillate fractions of a given oil raw material using the laboratory installation for oil distillation ARN-2.

The ARN-2 oil rectification apparatus is designed for distilling oil to a temperature of $470-500{ }^{\circ} \mathrm{C}$ to determine the potential content of petroleum products and their components in oil, as well as to obtain indicators for constructing distillation curves of the true boiling points of oil and its fractions, and to obtain oil fractions for studying their group hydrocarbon composition. The ARN-2 device consists of technological and electrical units mounted in a single metal frame. The processing unit is designed for distillation and consists of a cube with a capacity of 1 or 3 liters placed in the furnace, a distillation column, a condensation unit and receivers.

The electrical unit is designed for regulating and monitoring the process and consists of a recording potentiometer, an autotransformer, ammeters, and a control button.

Rectification column-nozzle type (nozzle) - spiral segments with a diameter of $5 \mathrm{~mm}$ and a height of 12 $\mathrm{mm}$ made of nichrome wire with a diameter of $0.5 \mathrm{~mm}$. The column has a diameter of $50 \mathrm{~mm}$ and a length of $1016 \mathrm{~mm}$. Equipped with electric heating and a thick layer of insulation. Temperature measurement is performed at three points (top, bottom, middle) using thermocouples, which are placed in pockets mounted in the column.

The linear separation capacity of the column corresponds to 20 theoretical plates. The lower part of the column is connected to the cube using a cap nut. For measuring the temperature of the cube is equipped with a pocket for a thermocouple.

The upper part of the column is connected to a condenser head consisting of a reverse refrigerator and a tap for selecting distillate, which then enters the receiver. At the place of distillate selection, a pocket for a thermocouple is installed in the refrigerator condenser, which records the temperature of the fraction selection. The heating of the cube and column is regulated by a laboratory autotransformer ammeters are included in the network to control the heating.

The individual and group hydrocarbon composition of various gasoline fractions was determined by chromatographic method using a gas chromatograph "CHROMATEK-KRISTALL 5000", shown in Fig.1 , following the standard ASTMD 6729. ${ }^{1,3}$

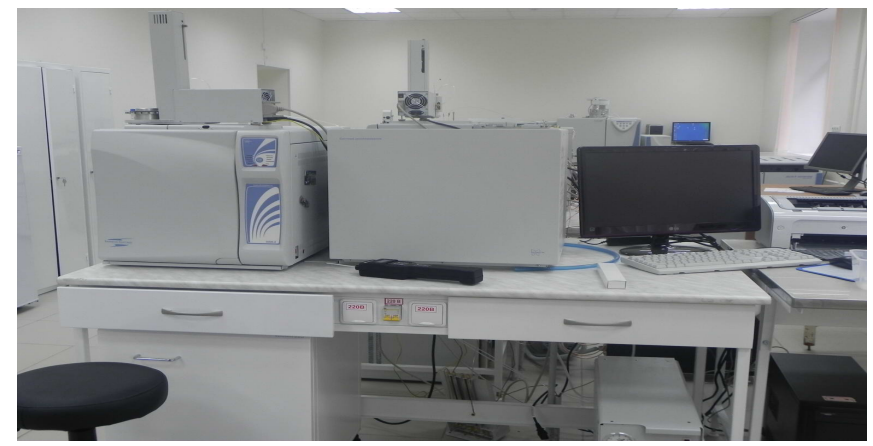

Fig.-1: Gas Chromatograph «CHROMATEK-KRISTALL 5000»

The fractional composition of the initial straight-run gasoline and isomerization products, as well as reforming was determined using the AFSA-2 analyzer (series \# 03051 2006), shown in Fig.-2 according to the guidelines "Determination of the fractional composition of gasoline on the AFSA-2 device".

The method consists of chromatographic separation of gasoline on a capillary column with a non-polar stationary phase, followed by registration of hydrocarbons by a flame ionization detector and automated processing of the obtained information using the software.

A representative sample of gasoline is introduced into a gas chromatograph equipped with a capillary column containing methyl siloxane as a solid phase deposited on the walls of a quartz capillary column. 
RASĀYAN J. Chem.

Vol. 13 | No. 4 |2639-2645| October - December | 2020

Under the action of the carrier gas-helium, the sample passes through a column in which its components are separated. Components are detected by the flame ionization detector when they are eluted from the column. The detector signal is processed by an electronic data storage system or an integrating computer. Each resulting peak is identified by comparing its retention index in a table or visually by comparison with standard chromatographs.

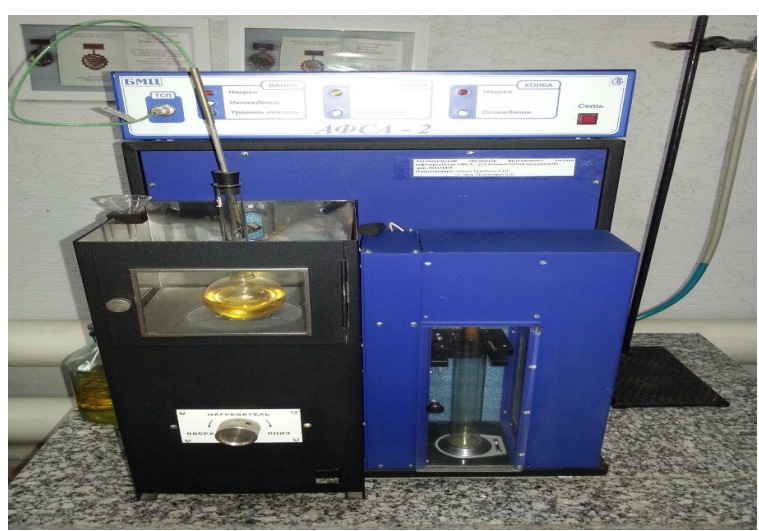

Fig.-2: AFSA-2 Device

\section{RESULTS AND DISCUSSION}

The Caspian oil field is mainly characterized by a significant content of hydrogen sulfide and light mercaptan and sulfide sulfur compounds, which require an unconventional approach to their processing. The oil mixture of the Caspian field is characterized by a significantly high yield of gasoline fractions (36.2\% by weight). The table shows a summary of the group hydrocarbon composition of light gasoline fractions (boiling point $62^{\circ} \mathrm{C}$ ) of Caspian oil. ${ }^{2}$

Table-1: Group Hydrocarbon Composition of Light Gasoline Fraction (Boiling Point $62^{\circ} \mathrm{C}$ ) of Caspian Oil

\begin{tabular}{c|c|c|c|c|c}
\hline Number of Carbon Atoms & N-paraffins & ISO-paraffins & Naphthenes & Aromatic & Total \\
\hline $\mathrm{C}_{3}$ & 0,032 & - & - & - & 0,025 \\
\hline $\mathrm{C}_{4}$ & 7,362 & 0,701 & - & - & 8,063 \\
\hline $\mathrm{C}_{5}$ & 20,923 & 16,859 & 1,393 & - & 39,175 \\
\hline $\mathrm{C}_{6}$ & 13,62 & 20,867 & 4,903 & 0,664 & 40,052 \\
\hline $\mathrm{C}_{7}$ & 2,53 & 4,554 & 3,314 & 0,405 & 10,813 \\
\hline $\mathrm{C}_{8}$ & 0,348 & 0,762 & 0,679 & - & 1,79 \\
\hline $\mathrm{C}_{9}$ & - & - & 0,056 & - & 0,056 \\
\hline total & 44,816 & 43,753 & 10,344 & 1,069 & 99,982 \\
\hline
\end{tabular}

Table-2: Physical Properties of Light Gasoline Fraction (Boiling Point $62^{\circ} \mathrm{C}$ ) of Caspian Oil

\begin{tabular}{c|c|c}
\hline Qualitative Indicators & Unit of Measurement & Value \\
\hline Density & $\mathrm{g} / \mathrm{ml}$ & 0,6579 \\
\hline Net calorific value & $\mathrm{kJ} / \mathrm{g}$ & 44,6 \\
\hline Higher calorific value & $\mathrm{kJ} / \mathrm{g}$ & 48,5 \\
\hline Saturated steam pressure & $\mathrm{mmHg}$ Art. & 22,14 \\
\hline Octane number & Motor method & 51.2 \\
\hline Octane number & Research method & 53.4 \\
\hline Fractional composition, & ${ }^{\circ} \mathrm{C}$ & $\begin{array}{c}\text { Boiling } \\
\text { point }\end{array}$ \\
TIC \% of distilled fractions & & $-0,5$ \\
\hline the beginning of the boil & & 1 \\
\hline $5 \%$ & &
\end{tabular}


RASĀYAN J. Chem.

Vol. 13 | No. 4 |2639-2645| October - December | 2020

\begin{tabular}{c|c|c}
\hline $10 \%$ & & 36,1 \\
\hline $20 \%$ & & 36,1 \\
\hline $30 \%$ & & 49,3 \\
\hline $40 \%$ & & 49,3 \\
\hline $50 \%$ & & 60,3 \\
\hline $60 \%$ & & 63,3 \\
\hline $70 \%$ & & 68,7 \\
\hline $80 \%$ & & 71,8 \\
\hline $90 \%$ & & 90,8 \\
\hline $95 \%$ & & 90,9 \\
\hline end of the boil & & 118 \\
\hline
\end{tabular}

Gasoline fractions of Caspian oil are characterized by low octane numbers (50-53). Due to the high content of mercaptans, they do not withstand testing on a copper plate, which requires the need for their purification when using isomerization and reforming processes as raw materials. The sulfur content in all distillates is high- $0.12-0.29 \%$ wt., except for the boiling point fraction $-120^{\circ} \mathrm{C}$, the acidity is also high4.1-6.3 mg KOH/100 cm3 of fuel. Gasoline fractions up to $200^{\circ} \mathrm{C}$ mainly consist of alkanes $(50-85 \%)$. The boiling point fraction- $62^{\circ} \mathrm{C}$ is a good raw material for the isomerization process (the content of $\mathrm{n}$ alkanes C5-C6 is 32\% per fraction). Mercaptan sulfur in the Caspian oil mixture is distributed unevenly among the fractions. In fractions the beginning of boiling $-62^{\circ} \mathrm{C}$ its content is the highest $(0.25-0.27 \%$ by weight), in heavy fractions it decreases. Due to the high content of volatile and environmentally harmful mercaptans in fractions, the quality requirements for Caspian oil for processing are significantly different from traditional ones. The table shows the results of the chromatographic analysis of the individual hydrocarbon composition of light gasoline fractions (boiling point- $62^{\circ} \mathrm{C}$ ) of Caspian oil, which is more effectively used as a raw material for the process of catalytic isomerization. ${ }^{8,9}$

Table-3: Individual Hydrocarbon Composition of Light Gasoline Fractions (Boiling Point-62 ${ }^{\circ} \mathrm{C}$ ) of Caspian Oil.

\begin{tabular}{|c|c|c|c|}
\hline No. & The Hydrocarbon Name & Wt. \% & Rpm. \% \\
\hline 1 & propane & 0,03 & 0,03 \\
\hline 2 & iso-butane & 0,70 & 0,82 \\
\hline 3 & butane & 7,21 & 8,11 \\
\hline 4 & t-2-butene & 0,09 & 0,10 \\
\hline 5 & iso-pentane & 16,48 & 17,32 \\
\hline 6 & pentane & 20,83 & 21,66 \\
\hline 7 & 2,2-dimethylbutane & 0,38 & 0,38 \\
\hline 8 & cyclopentane & 1,66 & 1,45 \\
\hline 9 & 2,3-dimethylbutane & 1,80 & 1,77 \\
\hline 10 & 2-methylpentane & 11,31 & 11,27 \\
\hline 11 & 3-methylpentane & 7,84 & 7,69 \\
\hline 12 & hexane & 12,74 & 12,58 \\
\hline 13 & 2,2-dimethylpentane & 0,11 & 0,10 \\
\hline 14 & methylcyclopentane & 3,67 & 3,19 \\
\hline 15 & 2,4-dimethylpentane & 0,26 & 0,25 \\
\hline 16 & benzene & 0,76 & 0,56 \\
\hline 17 & 3,3-dimethylpentane & 0,08 & 0,07 \\
\hline 18 & cyclohexane & 1,86 & 1,55 \\
\hline 19 & 2-methylhexane & 1,41 & 1,35 \\
\hline 20 & 2,3-dimethylpentane & 0,67 & 0,63 \\
\hline 21 & 1,1-dimethylcyclopentane & 0,24 & 0,21 \\
\hline 22 & 3-methylhexane & 1,89 & 1,79 \\
\hline 23 & c-1,3-dimethylcyclopentane & 0,48 & 0,42 \\
\hline
\end{tabular}


RASĀYAN J. Chem.

Vol. 13 | No. 4 |2639-2645| October - December | 2020

\begin{tabular}{l|c|c|c}
\hline 24 & t-1,3-dimethylcyclopentane & 0,42 & 0,37 \\
\hline 25 & 3-ethylpentane & 0,19 & 0,17 \\
\hline 26 & t-1,2-dimethylcyclopentane & 0,89 & 0,77 \\
\hline 27 & heptane & 2,31 & 2,20 \\
\hline 28 & methylcyclohexane & 1,34 & 1,13 \\
\hline 29 & 1,1,3-trimethylcyclopentane & 0,10 & 0,09 \\
\hline 30 & ethylcyclopentane & 0,15 & 0,13 \\
\hline 31 & 2,4-dimethylhexane & 0,06 & 0,05 \\
\hline 32 & ctc-124trimethylcyclo-pentane & 0,11 & 0,09 \\
\hline 33 & tcc-123-trimethylcyclo-pentane & 0,16 & 0,13 \\
\hline 34 & toluene & 0,45 & 0,34 \\
\hline 35 & 2,3-dimethylhexane & 0,06 & 0,06 \\
\hline 36 & 2-methylheptane & 0,27 & 0,25 \\
\hline 37 & 4-methylheptane & 0,06 & 0,06 \\
\hline 38 & 3-methylheptane & 0,11 & 0,10 \\
\hline 39 & 1c2t3-trimethylcyclopentane & 0,32 & 0,27 \\
\hline 40 & t-1,4-dimethylcyclohexane & 0,13 & 0,11 \\
\hline 41 & t-1,2-dimethylcyclohexane & 0,09 & 0,08 \\
\hline 42 & octane & 0,32 & 0,30 \\
\hline & Total & 100,00 & 100,00 \\
\hline
\end{tabular}

As can be seen from Table-3, the yield of the low-boiling gasoline part is significant, the content in the boiling point fractions- $62^{\circ} \mathrm{C}$ of butane-pentane fractions- $\mathrm{C}_{4}-\mathrm{C}_{5}$ and pentane-hexane fractions $-\mathrm{C}_{5} \mathrm{C}_{6}$, respectively, is 43.5 and $32.4 \%$ by weight. The sum of the heptane and octane fractions- $\mathrm{C}_{5}-\mathrm{C}_{6}$ total-2.65 mass.

Analysis of the individual hydrocarbon composition and physical and chemical properties of light gasoline fractions shows ${ }^{1,3}$ that the oil of the Caspian field is light, medium-paraffin, mainly a light hydrocarbon raw material with a significant content of hydrogen sulfide and light mercaptan sulfur compounds, which require an unconventional approach to their processing. The table shows the potential content of the composition of straight-run gasoline of Caspian oil. ${ }^{6}$

Table-4: Potential Content and Narrow Fractional Composition of Straight-run Gasoline of Caspian Oil.

\begin{tabular}{c|c|c|c}
\hline No. & $\begin{array}{c}\text { The Name } \\
\text { Fraction, }{ }^{\circ} \mathrm{C}\end{array}$ & $\begin{array}{c}\text { The Output of Individual } \\
\text { Fractions, } \% \text { wt. }\end{array}$ & $\begin{array}{c}\text { Total Output, } \\
\% \text { wt. }\end{array}$ \\
\hline 1 & Boiling Point-62 & 5,31 & 5,31 \\
\hline 2 & $62-70$ & 1,20 & 6,51 \\
\hline 3 & $70-85$ & 3,01 & 9,52 \\
\hline 4 & $85-100$ & 3,41 & 12,93 \\
\hline 5 & $100-120$ & 5,12 & 18,05 \\
\hline 6 & $120-130$ & 3,21 & 21,26 \\
\hline 7 & $130-140$ & 2,61 & 23,87 \\
\hline 8 & $140-150$ & 3,11 & 26,98 \\
\hline 9 & $150-160$ & 2,11 & 29,09 \\
\hline 10 & $160-170$ & 2,91 & 32,00 \\
\hline 11 & $170-180$ & 2,31 & 34,31 \\
\hline 12 & $180-190$ & 2,21 & 36,52 \\
\hline 13 & $190-200$ & 2,41 & 38,93 \\
\hline
\end{tabular}

Kerosene fraction $200-250^{\circ} \mathrm{C}$ and $250-300^{\circ} \mathrm{C}$ Oil of the Caspian field is mainly represented with a significant content of total sulfur (0.62 -1.24\% of turnover) mercaptan and sulfide sulfur compounds (49.2 and $37.8 \%$ of the total turnover of sulfur-containing compounds) and the content of aromatic hydrocarbons $(14.71-22.4 \%$ of the turnover), which require unconventional approaches to their processing and the use of the resulting oil product. ${ }^{5,7}$ 
RASĀYAN J. Chem.

Vol. 13 | No. 4 |2639-2645| October - December | 2020

Table-5: Group Hydrocarbon Composition of the Broad Gasoline Fractions of Caspian Oil.

\begin{tabular}{|c|c|c|c|c|c|c|c|}
\hline \multirow{2}{*}{$\begin{array}{c}\text { Fraction } \\
\text { Selection } \\
\text { Temperature, } \\
{ }^{\circ} \mathrm{C}\end{array}$} & \multirow{2}{*}{$\begin{array}{l}\text { Oil } \\
\text { Yield, } \\
\text { rpm } 1 . \\
\%\end{array}$} & \multirow{2}{*}{$\begin{array}{c}\text { Density at } \\
20^{\circ} \mathrm{C}\end{array}$} & \multicolumn{2}{|c|}{ Sulfur Content, $\%$} & \multicolumn{3}{|c|}{ Hydrocarbon Content, \% rpm. } \\
\hline & & & $\begin{array}{l}\text { Com } \\
\text { mon }\end{array}$ & Mercaptan & Aromatic & Naphthenic & Methane \\
\hline 65 & 7.72 & 636.1 & 160 & & 0.81 & 4.3 & 95 \\
\hline $65-100$ & 9.23 & 704.3 & 64 & 51.6 & 4.03 & 30 & 66 \\
\hline $100-150$ & 14.4 & 747.2 & 67 & 42.5 & 17.3 & 34.9 & 50.4 \\
\hline $150-200$ & 13.35 & 781.2 & 0.46 & 52.2 & 21 & 24.4 & 54.5 \\
\hline
\end{tabular}

Table-6 shows the Potential Contents and Fractional Composition of Straight-run Kerosene Fractions of Caspian Oil.

Table-6: Characteristics of Kerosene Fractions of Caspian Oil

\begin{tabular}{c|c|c|c|c}
\hline \multirow{2}{*}{ Indicators } & Unit & \multicolumn{2}{|c|}{$\begin{array}{c}\text { Fraction Selection } \\
\text { Temperature, }\end{array}$} & \multirow{2}{*}{\begin{tabular}{c} 
Standard \\
GOST-11244- \\
\cline { 3 - 4 }
\end{tabular}} \\
\cline { 3 - 4 } & $200-250$ & $250-300$ & 65 \\
\hline Oil Yield & $\%, \mathrm{rpm}$ & 10.92 & 11.30 & up to $50 \%$ \\
\hline Density at $20^{\circ} \mathrm{C}$ & $\mathrm{kg} / \mathrm{m}$ & 805.45 & 834.2 & \\
\hline Total Sulfur & $\%, \mathrm{rpm}$ & 0.62 & 1.24 & 0.1 \\
\hline mercaptan sulfur & $\%, \mathrm{rpm}$ & 49.5 & 37.8 & \\
\hline $\begin{array}{c}\text { Aromatic } \\
\text { Hydrocarbon } \\
\text { Content }\end{array}$ & $\%, \mathrm{rpm}$ & 14.71 & 22.74 & \\
\hline $\begin{array}{c}\text { Smoke-free } \\
\text { Height Content }\end{array}$ & $\mathrm{mm}$ & 24.52 & 19.12 & 25 \\
\hline
\end{tabular}

Table-7: Characteristics of Diesel Fractions of Caspian Oil.

\begin{tabular}{c|c|c|c|c}
\hline \multirow{2}{*}{ Indicators } & \multirow{2}{*}{ Unit } & \multicolumn{3}{|c}{ Fraction Selection Temperature } \\
\cline { 3 - 5 } & & $250-300^{\circ} \mathrm{C}$ & $300-350^{\circ} \mathrm{C}$ & $350-370{ }^{\circ} \mathrm{C}$ \\
\hline Oil Yield & $\%, \mathrm{rpm}$ & 11.54 & 10.21 & 3.12 \\
\hline $\begin{array}{c}\text { Density at } \\
20^{\circ} \mathrm{C}\end{array}$ & $\mathrm{kg} / \mathrm{m}^{3}$ & 806.15 & 854.1 & 863.52 \\
\hline $\begin{array}{c}\text { Sulfur } \\
\text { Content }\end{array}$ & $\% \mathrm{rpm}$ & 0.61 & 2.08 & 3.08 \\
\hline Kinematic & $\mathrm{mm}^{2} / \mathrm{s}$ & 2.27 & 5.791 & 10.2 \\
\hline Temperature & ${ }^{\circ} \mathrm{C}$ & -27 & 3.1 & 17.2 \\
\hline
\end{tabular}

\section{CONCLUSION}

Physical and chemical properties and individual hydrocarbon composition of gasoline and kerosene-gas oil fractions of the Caspian field, Atyrau region, Republic of Kazakhstan were studied. It is shown that the oil of the Caspian field is medium paraffin, mainly a light hydrocarbon raw material with a high yield of gasoline fractions ( $36.2 \%$ by weight) and a significant content of hydrogen sulfide, light mercaptan and sulfide sulfur compounds, which require a special approach to their effective processing. Light gasoline fractions (boiling point $-62^{\circ} \mathrm{C}$ ) of Caspian oil, effectively used as a raw material for the process of catalytic isomerization, and the resulting product-isomerizate used as a component of commercial highoctane environmentally friendly automobile gasoline and for the production of hydrocarbon solvents, 
RASĀYAN J. Chem.

Vol. 13 | No. 4 |2639-2645| October - December | 2020

kerosene and diesel fractions after their hydrocatalytic processing used as a component for the production of jet and diesel fuel.

\section{REFERENCES}

1. V.V. Boldinov, E.A. Esipko, A.A. Kamensky, Chemistry and Technology of Fuels and Oils, 2(6), 51(1996)

2. N.K.Nadirov, Yu.A. Zaykin, A.E. Kaldygozov, Oil and Gas, 3(2), 63(2012)

3. A.E. Kaldygozov, G.Sh. Erkebaeva, N.K.Nadirov, Yu.A. Zaykin, E. Kaldygozov, Oil and Gas, 3(81), 73(2014)

4. A.E. Kaldygozov, A. Taldybaeva, D. Kadirbaev, E.K.Kaldygozov, Oil and Gas, 2(86), 145(2015)

5. P.A. Pikula, A.K. Golovko, V.F. Kamyanov, Eurasian Chemical Technology Journal, 3(1), 205(2001), DOI:10.18321/ectj570

6. D. S. Redwan, D. S. Redwan, Journal Petroleum Science and Technology, 17,9(1999) DOI: $10.1080 / 10916469908949756$

7. M.K. Andari, H Bchbehani and A. Stanislaus, Journal Fuel Science and Technology International 14(7), 939(1996), DOI:10.1080/08843759608947622

8. H. Zhao Journal Petroleum Science and Technology. 25(5) 569-576 (2007)

9. T.O. Omaraliev, L.Suyunova, I.R. Abdukhalikova, E.K. Kaldygozov, S.K. Kerimbekov, Chemistry and Technology of Fuels and Oils, 13(6), 584(1990)

10. Susilawati, M. Hanifuddin and Y. P. Gultom Rasayan Journal of Chemistry, 12(3), 1043(2019), DOI: $10.31788 /$ RJC.2019.1235166

11. A. A. Anarbayev, G. M. Ormanova, B.N. Kabylbekova, N.A. Vysotskaya, B.Kh. Kucharov Rasayan Journal of Chemistry, 13(4), 2180(2020), DOI:10.31788/RJC.2020.1345888

[RJC-5971/2020] 